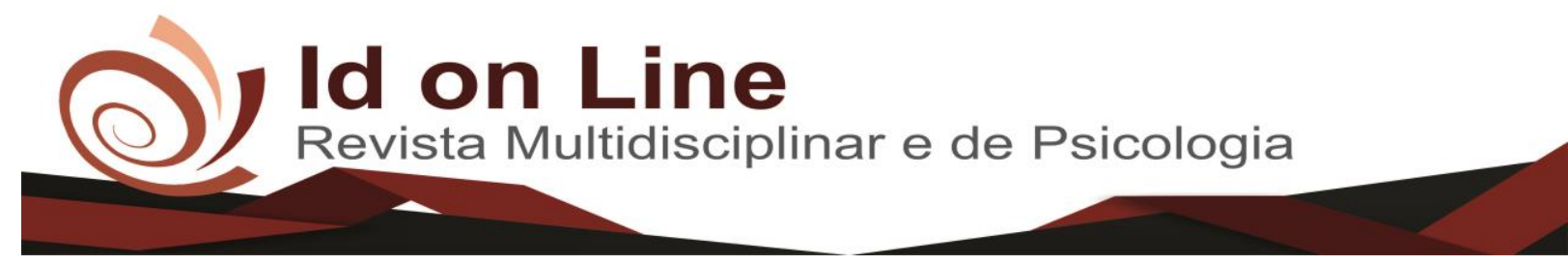

Artigo

\title{
Assédio Moral de LGBT no âmbito Organizacional
}

\author{
Maria Patrícia de Alencar ${ }^{1}$; Nágela Cristina Gonçalves dos Santos ${ }^{2}$; Miguel Ângelo Silva de Melo ${ }^{3}$
}

\begin{abstract}
Resumo: $\mathrm{O}$ assédio moral frente aos sujeitos LGBT acontece pela orientação sexual ou pela identidade de gênero adotada pelo grupo, uma vez que é praticado por pessoas que não sabem conviver com as diferenças. O objetivo geral do trabalho se propõe a identificar a existência do assédio moral de LGBT em Organizações Empresariais na Região Metropolitana do Cariri. A pesquisa caracteriza-se como básica, exploratória, descritiva, qualitativa, sendo realizado dois estudos de caso no município de Juazeiro do Norte-CE, nos dias 24 e 26 de outubro de 2017. Os sujeitos da pesquisa foram um homossexual gay, e uma empresária heterossexual. O local e sujeito foi selecionado por conveniência e acessibilidade. Foi utilizado a entrevista semiestruturada, e a análise dos dados foi feita adotando-se a técnica de análise de conteúdo. A empresária da organização pesquisada já impediu e demitiu do trabalho alguém por causa da orientação sexual, afirma a prática da Homofobia ou Assédio no ambiente de trabalho frente ao grupo praticando de uma forma cruel. Sente-se realizada com uma situação de exclusão e desrespeito aos LGBT dizendo que eles vão contra os seus princípios. Menciona que sua organização não tem nenhum prejuízo em não contratar um integrante do grupo, e sim, que pode apresentar prejuízo se houver o processo de contratação. Através da investigação se tornou possível constatar que o assédio LGBT é uma constante recheada pelo silêncio e pelo tabu. O estudo conclui enfatiza que quando não se tem como trabalhar a pessoa não terá condições mínimas de viver com dignidade, tendo em vista que permite que se perceba que as empresas devem se preocupar com a responsabilidade social e com o impacto que a Lgbtfobia poderá proporcionar na vida das pessoas, no ingresso destas ao mercado de trabalho ou a permanência nas organizações.
\end{abstract}

Palavras-chave: Assédio Moral. LGBT. Âmbito Organizacional. Homofobia. A Dignidade da Pessoa Humana.

\section{LGBT Moral Assistance In The Organizational Framework}

Abstract: Bullying agains LGBT subjects occurs because of the sexual orientation or gender identity adopted by the group, as it is practiced by people who do not know how to live with differences. The general aim of this study is to identify the existence of bullying of LGBT in Business Organizations in the Metropolitan Region of Cariri. The research is characterized as basic, exploratory, descriptive, and qualitative. Two case studies were carried out in the city of Juazeiro do Norte-CE, on October 24 and 26, 2017. The subjects of the research were a gay homosexual, and one Heterosexual executive. The place and subject was selected for convenience and accessibility. The semi-structured interview was used, and the analysis of the data was done adopting the content analysis technique. The businesswoman of the research organization has already prevented and dismissed someone because of sexual orientation, shows the practice of Homophobia or Harassment in the workplace against the group practicing in a cruel way. It is carried out with a situation of exclusion and disrespect to the LGBT saying that they go against its principles. He mentions that his organization has no detriment in not hiring a member of the group, but that he can present damages if there is a hiring process. Through the investigation it became possible to verify ${ }^{1}$ Administradora pelo Centro Universitário Doutor Leão Sampaio/UNILEÃO, patriciaalencar133@ gmail.com;
${ }^{2}$ Graduanda do Curso de Enfermagem da Faculdade de Juazeiro do Norte/FJN, nacristina1050@ gmail.com;
${ }^{3}$ Doutor em Sociologia pela Universidade Federal de Pernambuco (UFPE). Mestre em Educação Intercultural com ênfase em Antropologia
Social pela Universidade de Hamburgo/ Alemanha. Mestre em Direito Internacional com ênfase em Criminologia Internacional pela
Universidade de Hamburgo/ Alemanha. Docente do curso de Direito do Centro Universitário Doutor Leão Sampaio (UNILEÃO). Docente do
curso de Direito e docente do curso de Pedagogia da Faculdade de Ciências Humanas do Sertão Central (FACHUSC). Pesquisador-líder do
Laboratório de Estudos da Violência (LIEV) do Centro Universitário Doutor Leão Sampaio (UNILEÃO). Pesquisador-líder do Núcleo de
Estudos de Etnicidade, Gênero e Relações Étnico-raciais (NEEGRA). Licenciado em Pedagogia pela Faculdade Kurios (FAK) e Advogado de
Direitos Humanos. E-mail: crioulo.miguelangelo.melo@ gmail.com.

413 Id on Line Rev. Mult. Psic. V.12, N. 40. 2018 - ISSN 1981-1179

Edição eletrônica em http://idonline.emnuvens.com.br/id 
that the LGBT harassment is a constant stuffed by the silence and the taboo. The study emphasizes that when one has no way of working one will not have minimal conditions of living with dignity, since it allows to perceive that companies should be concerned with social responsibility and with the impact that Lgbt fobia can provide in people's lives, whether they start to work or stay in organizations.

Keywords: Moral Harassment. LGBT. Organizational Scope. Homophobia. The Dignity of the Human Person.

\section{Introdução}

A preocupação com o capital humano deve ser prioridade nas organizações públicas e privadas, nas organizações do terceiro setor e na academia, bem como ocupar posição de destaque como objeto de estudo em artigos, dissertações, teses e livros, pois quando o mesmo é estrategicamente valorizado e trabalhado todo o seu potencial as chances das organizações atingirem patamares elevados é muito maior.

A empresa tem de ter em mente que o capital humano é o seu maior patrimônio. Embora as pessoas estejam imersas em um ambiente que predomina o capitalismo, em momento algum pode-se desvalorizar as pessoas por qualquer motivo, seja por cor, raça, classe social, religião e principalmente orientação sexual, dentre outros.

A competência de qualquer indivíduo é detectada através de ações práticas, não no julgamento de que ele não atende ao que a empresa busca de conhecimentos, habilidades e atitudes de um profissional para que o mesmo atinja os resultados esperados pelas organizações. A medida que as pessoas têm a oportunidade de mostrar o seu trabalho os gestores das empresas têm em mãos ferramentas e técnicas que permitam avaliar se aquela pessoa atende as necessidades e desejos do cargo e da organização, uma vez que elas aspiram resultados em curtos espaços de tempo, requerendo dos colaboradores e de todos os envolvidos com a organização concentrações de esforços para atingirem o mesmo objetivo e alinhar os objetivos da organização com os dos colaboradores.

Na era da globalização é visível a necessidade de nos atentar para a questão do assédio moral, pois a sua prática tornou-se mais constante. A cobrança de resultados faz com que as pessoas usem desse instrumento de terror psicológico para conseguir atingir os objetivos, porém

ele traz sérios prejuízos principalmente para quem é assediado. É necessário sermos mais responsáveis e identificarmos os seus reais danos para não o praticarmos. $\mathrm{O}$ assédio moral frente 
aos sujeitos LGBT acontece pela orientação sexual ou pela identidade de gênero adotada pelo grupo, que vai contra a cultura vivenciada por grande parte dos integrantes da sociedade, das empresas, dos gestores e dos envolvidos no contexto do trabalho. É praticado por pessoas que não sabem conviver com as diferenças. Embora as pessoas vivam em pleno século XXI muitas desconhecem a definição da sigla LGBT, quem são os membros participantes deste grupo, o seu significado e sua importância, a luta dos mesmos para diminuir a discriminação, aumentar os direitos e as oportunidades, principalmente frente ao âmbito do trabalho.

Tem-se a necessidade de entender e esclarecer porque as pessoas, a sociedade, as empresas e todos os envolvidos na sua cadeia produtiva os diferenciam de uma forma tão cruel, o qual ferem a dignidade humana dos mesmos. É preciso sair dessa zona de desconhecimento, passar a explorar e descrever o assédio moral no trabalho e após essa noção geral, abordar o assédio frente à população, comunidade ou grupo LGBT. Diante disso, o trabalho visa encontrar resposta para a seguinte pergunta de partida: De que forma ocorre o assédio moral de LGBT no âmbito organizacional?

A pesquisa possui como objetivo geral identificar a existência do assédio moral de LGBT na organização pesquisada verificando-se as prováveis causas diante da percepção de uma empresária, e constatar este assédio através das experiências de um representante do grupo. E como objetivos específicos: explorar e descrever o assédio moral existente nas organizações; constatar a (s) causa (s) que motiva a prática do assédio moral nas organizações; despertar a necessidade de maior informação sobre o assunto assédio moral; conscientizar os gestores da responsabilidade social que eles deveriam ter, para a preservação do maior patrimônio das empresas que são as pessoas, os colaboradores e acima de tudo a necessidade de respeitar o outro; realizar dois estudo de caso para entender o lado do assediado e a postura do assediador frente a inserção e permanência dos membros LGBT no âmbito organizacional.

O estudo da temática é fundamental, principalmente por tornar público um pouco da dificuldade que o grupo LGBT enfrenta no processo de inserção no mercado de trabalho como na permanência dos mesmos em seus postos de trabalho. Pelo fato da organização dificultar a entrada dos LGBT devido à orientação sexual ou pela identidade de gênero adotada pelo grupo. Tal motivo torna-se decisivo para o processo de admissão como demissão no trabalho. Tornase relevante porque o problema é de extrema importância visto que o assédio e a homofobia apresentados no artigo precisam ser combatidos, prevenidos. Tem-se necessidade de luta, de 
participação, é preciso que as pessoas ajam de forma mais ativa para a construção de uma nova postura, requerida para a melhoria de vida de todos.

\title{
Assédio Moral no Trabalho
}

É de extrema importância o estudo do Assédio Moral no Trabalho. Para fundamentar:

\begin{abstract}
Pode-se afirmar, sem medo de errar, que o assédio moral nas relações de trabalho é um dos problemas mais sérios enfrentados pela sociedade atual. Ele é fruto de um conjunto de fatores, tais como a globalização econômica predatória, vislumbradora somente da produção e do lucro, e a atual organização do trabalho, marcada pela competição agressiva e pela opressão dos trabalhadores através do medo e da ameaça. Esse constante clima de terror psicológico gera, na vítima assediada moralmente, um sofrimento capaz de atingir diretamente sua saúde física e psicológica, criando uma predisposição ao desenvolvimento de doenças crônicas, cujos resultados a acompanharão por toda a vida (FERREIRA apud, NASCIMENTO, 2011, p. 13,14).
\end{abstract}

Falar de assédio moral é falar de algo que sempre existiu nas interações sociais. Ao aprofundar o seu estudo percebe-se que as pessoas conviviam em meio a ele e não sabiam identificá-lo ou como se posicionar diante dele. Em todo lugar do mundo o assédio moral acontece e cada país conhece-o por um nome específico tais como: Mobbing e o mais chamado atualmente é psicoterror (SOARES; DUARTE, 2014).

Esse assunto está chamando a atenção de várias pessoas, inclusive médicos e a sociedade como um todo, para conhecer como ele se manifesta, quais os impactos causados na vida de quem é vítima desse problema, como preveni-lo e todas as situações que o assunto nos leva. Pela falta de uma lei específica federal que criminalize o assédio moral, o mesmo existe e ocorre com maior facilidade, o que existe são projetos de lei, sendo assim as organizações e todos os envolvidos com ela, sentem maior liberdade para praticarem. Às vezes o conhecimento é tão grande sobre o assunto que o assédio acontece e quem sofre nem percebe que foi vítima.

A forma como se trabalhava as relações de trabalho sempre foi o de aumentar a produtividade e o lucro da empresa, porém utilizavam toda forma de alcançá-los, mesmo que para isso fosse preciso usar do assédio moral, pois pela falta de conhecimento do assunto e da não percepção que era errado, ou visto como um psicoterror a vida humana e não ser colocado como ato ilegal, não se preocupava se causava prejuízo para os assediados, ou até que ponto ia os danos provocados para todo o contexto social. Conhecer o real significado do que seja Assédio nos permite identificar com maior facilidade se o mesmo já ocorreu conosco, se ocorre 
com parentes, com amigos e principalmente com a população aqui em estudo, como também saber todos os detalhes que cerca esse assunto. Segue então a definição:

Define o assédio moral no trabalho como qualquer conduta abusiva (gesto, palavra, comportamento, atitude...) que atente, por sua repetição ou sistematização, contra a dignidade ou integridade psíquica ou física de uma pessoa, ameaçando seu emprego ou degradando o clima de trabalho (HIRIGOYEN 2002a, p.17 apud SOARES; DUARTE, 2014, p. 6).

Através dessa definição pode-se caracterizar, detalhando-se o Assédio Moral. Inicialmente é uma conduta abusiva, isto é, a maneira de conduzir a relação de trabalho extrapola o poder que cada indivíduo tem dentro de um cargo ou organização. As pessoas através do ter ou do achar que tem poder, passam a se enxergar como donos da razão e no direito de praticar atos, podendo-se até manipular a situação a seu benefício e da organização. Foge-se as regras, a lei não é respeitada ou cumprida e o limite não existe. Caracteriza-se também pela repetição ou sistematização, ou seja, o assédio moral é reproduzido de forma contínua, alimenta-se pelo processo de repetição, agravando ainda mais a situação. Não foge à regra, mas pode ocorrer de o assédio apresentar-se somente uma vez, porém a gravidade ou o impacto que a situação gera no indivíduo é extremamente destruidor.

Outra característica é que o assédio vem para ameaçar o emprego do indivíduo que sofre a ação e vem degradar o clima organizacional. Visto que este não consegue lidar com a situação de desconforto e desigualdade no trabalho, passando-se a ter várias dificuldades e uma delas é a pouca ou nenhuma parceria entre as pessoas do seu trabalho, pois este problema interfere nas relações de proteção e vínculo empregatício das pessoas que estejam do lado do assediado. Frente aos objetivos/etapas "o (s) assediador (es) se vale (m) de três objetivos intermediários: isolar, desestabilizar e difamar o assediado, os quais podem ser encarados como fases ou etapas e que podem se dar em diferentes ordens, e mesmo de forma interligada, muitas vezes (mas não sempre) com o intuito de se atingir o objetivo final de excluir o assediado do contexto de produção" (SOARES, 2006, p.55).

Diversas são as causas que levam uma pessoa a assediar outra, tais como mostrar o poder que a mesma tem no ambiente de trabalho, a dificuldade de aceitação de diferenças entre os indivíduos independentes das apresentadas, a intenção de se desfazer de um contrato de trabalho sem tantos prejuízos financeiros, o fato da pessoa assediante se sentir ameaçada por alguma razão. Isto é, em resumo a principal causa do assédio no trabalho é fazer prevalecer à opinião e a vontade do assediante (SOARES, 2006). 
Neste sentido, Soares destaque que o assédio moral traz consequências para o assediado, tendo em vista que este produz "uma diversidade de danos, os quais podem ser de natureza física, afetiva, cognitiva e/ou social” (IBID., 2006, p.55). Em relação ao físico seguem alguns problemas que acarretam como: abalo do sistema nervoso, disfunções do sistema gástrico, interferência dos movimentos, pois afeta o sistema musculoesquelético, assim como o sistema endócrino, e interfere também o sistema circulatório (SOARES, 2006). Em relação ao afetivo é nítido o descontrole emocional que acontece com o indivíduo, tristezas, angústias, irritabilidade passa a ser sua companhia constante. Depressões, ansiedade, são sintomas visíveis. Repercute nesse caso uma série de reações psicológicas e comportamentais nesses indivíduos. Em relação ao cognitivo trazem patologias cerebrais, que necessitam ser estudadas, trabalhadas e tratadas (IBID., 2006).

Já em relação ao social entende-se que os indivíduos passam a reduzir o grau de interação social, seja com os colegas de trabalho, seja com a família (amigos), afetando assim, também, a relação com o seu parceiro (a). Por conseguinte, diante da ocorrência de ações de assédio, desenvolvem-se consequências em diversos contextos sociais da vida da vítima, levando-o a um abandono auto subjetivo de sua própria condição enquanto ser humano, tais como, danos interpessoais para o resto de suas vidas, danos estes irreparáveis.

O assédio moral também traz consequências ou prejuízos para as organizações assim como destaca Soares (2006) a empresa é afetada na produtividade e na lucratividade, porque os gestores estão fortemente preocupados com isso e esquecem que quando assediam os colaboradores no ambiente de trabalho afetam o indivíduo de tal forma que o deixa menos produtivo, afeta o desenvolvimento do seu trabalho dentro da empresa, em algum momento o funcionário pode precisar ir ao médico, gastar com medicamentos, passar a ter um nível de absenteísmo maior. Podendo até adquirirem uma doença ocupacional, que ao ser constatada a empresa fica proibida de demiti-lo e terá que arcar com todas as despesas necessárias à saúde da pessoa.

Os funcionários podem vir a entrarem com processos judiciais solicitando indenizações, ou reparação de danos causados pelo assédio moral no ambiente de trabalho. Sendo realmente comprovadas as queixas o custo dessa reparação se torna muito grande para a empresa praticante. Diante desses motivos e de outros, a empresa poderia trabalhar a responsabilidade social, a organização deveria pensar, adotar uma postura consciente dos seus atos, valorizar as pessoas que interagem com ela, pois somente através de boas gestões, de um bom 
relacionamento com a equipe de trabalho consegue-se qualquer resultado, e principalmente os positivos almejados constantemente pela empresa. Se faz necessário destacar a responsabilidade social das empresas, entender um pouco sobre responsabilidade empresarial, pois os gestores das empresas têm de ter tal conhecimento como também executar aquilo que é de seu dever.

\begin{abstract}
A ideia de responsabilidade social, nos termos em que se coloca a questão, pressupõe que a atividade empresarial envolve o compromisso de toda a cadeia produtiva da empresa: clientes, funcionários e fornecedores, além das comunidades, do ambiente e da sociedade, como um todo. A ideia está relacionada com a teoria dos stakeholders que seriam os indivíduos ou grupos que dependem da organização para alcançar seus interesses ou objetivos próprios e dos quais a organização também depende para alcançar suas metas (JOHNSON; SCHOLES 1997, apud MENEGASSO, 2001, p. 66).
\end{abstract}

A organização é uma das responsáveis de forma direta ou indireta por todos os problemas enfrentados na sociedade, ela exerce poder de decisão nos mais variados assuntos, e capazes de desenvolver todo e qualquer indivíduo em sociedade, conferindo-os oportunidades iguais. Quanto a classificação do assédio moral, Carvalho menciona que:

[...] a conduta perversa que imputa dor e sofrimento psíquico à vítima, destruindo sua autoestima, ferindo sua dignidade e personalidade, pode partir tanto do empregador ou superior hierárquico a este subordinado (Assédio Moral Vertical Descendente), como de algum colega de trabalho (Assédio Moral Horizontal) ou até mesmo de um subordinado contra um superior hierárquico (Assédio Moral Vertical Ascendente). (IBID., 2009, p. 69).

Acompanhando esse pensamento as organizações passam a maximizar as chances de apoio, parcerias e sucesso, e minimiza os pontos errados que teria se não fosse esse progresso de pensamento. Ampliando o compromisso com a sociedade aumentamos e fortalecemos a garantia de direitos respeitados e damos menos espaço para o processo de discriminação e sentimento de egoísmo em só pensar na empresa como contexto econômico, visando só no lucro. É desafio para as organizações adotarem essa postura, e se adotarem, a preocupação e o cuidado na sua permanência.

\title{
LGBT e Empregabilidade: Homofobia ou Assédio?
}

De acordo com o governo estadual de São Paulo (2014): LGBT é uma sigla conhecida internacionalmente para representar um grupo, uma comunidade ou população minoritária na 
sociedade em termos de direitos. A sigla é composta pelos seguintes membros: Lésbicas, Gays, Bissexuais, Travestis e Transexuais. Para uma melhor compreensão definiremos a representação de cada membro participante da sigla: Lésbica é a nomenclatura usada para classificar as pessoas ou indivíduos que se atraem afetiva ou sexualmente por pessoas do mesmo sexo ou gênero, o qual nesse caso é o feminino (sujeitos envolvidos são duas mulheres); gay é a nomenclatura usada para classificar as pessoas ou indivíduos que se atraem afetiva ou sexualmente por pessoas do mesmo sexo ou gênero, o qual nesse caso é o masculino (sujeitos envolvidos são dois homens); bissexual é a nomenclatura usada para classificar as pessoas ou indivíduos que se atraem afetiva ou sexualmente por pessoas de ambos os sexos, o qual nesse caso é o homem e a mulher (sujeito envolvido se relaciona com um homem e com uma mulher); travesti é a nomenclatura usada para classificar as pessoas que nasceram biologicamente com o sexo masculino e se vestem e comportam como mulheres, adotando postura feminina diante da sociedade, sem desprezar o desejo e o uso pelo órgão masculino, ou seja, representa a figura masculina vestida de feminina.

A sexualidade desses sujeitos se torna mais evidente pela questão da aparência (constata-se a posição de contramão a dicotomia dos gêneros, uma vez que estes sujeitos não abrem mão da identidade biológica, apesar de adotarem a identidade social); transexual é a nomenclatura usada para classificar a pessoa que assume uma identidade sexual diferente da visualizada no nascimento, ou seja, a pessoa tem uma identidade social que não condiz com a identidade biológica do ser homem ou do ser mulher.

A percepção de como a pessoa se ver é tão marcante que ela nem sempre, mas pode vir a modificar o seu corpo através de vários métodos dentre eles a cirurgia de mudança de sexo. Vale ressaltar que o interesse na mudança de sexo nem sempre é manifestada, a pessoa somente se ver como o sexo oposto (constata-se a necessidade de conquistar o tratamento relacionado ao gênero social e não ao biológico).

\section{Mundo do Trabalho para os LGBT}

Há muita dificuldade para os LGBT ingressarem no âmbito do trabalho. Segundo Ferreira (2007) existe uma cultura onde as pessoas internalizam que os LGBT ou homossexuais 
devem e só podem ocupar cargos já estabelecidos, ou selecionados. Com a visão de que mais se adequam aos seus hábitos:

As pessoas têm costume de ligar a pessoa que é gay diretamente com prostituição, ou seja, que um gay não pode ter inteligência, que o gay não pode ter uma família, não pode ser respeitado, não pode ter um trabalho. Porque a sociedade colocou um rótulo que todo gay tá ligado à prostituição (MARROM apud FERREIRA, SOUZA; MOREIRA, 2015, p. 1576).

Ai já começa a discriminação que um homossexual não pode ou não é de costume, ocupar cargos diferentes do comum e da cultura presenciada na sociedade. Vale ressaltar que a profissão escolhida por eles, depende do interesse que os mesmos têm pelas áreas. $\mathrm{O}$ que acontece é só a dificuldade ou as barreiras encontradas para realização ou concretização do sonho, do alcance da profissão, pois é difícil quebrar esse paradigma, mas não é um caso impossível, à medida que um homossexual consegue cargos até então inimagináveis ao olhar dos preconceituosos. Os LGBT são em minoria e os heterossexuais que são pessoas que se relacionam afetivo/sexualmente pelo sexo oposto, ou seja, homem com mulher ou vice e versa, tentam dominar o pensamento e a influência das demais pessoas, para que assim os direitos dos LGBT continuem sempre minimizados.

De modo que, ao entrarem no mercado de trabalho os Gays são alvos de discriminação, intolerância e homofobia. Se o indivíduo tem as características afeminadas como também os que não têm problema em se assumirem sofrem assédio moral. Vários são os constrangimentos e humilhações. Os homossexuais são vítimas desse assédio e no trabalho tem-se uma extensão do preconceito da sociedade (FERREIRA, SOUZA E MOREIRA, 2015).

A crise gerada pelo olhar do outro pode refletir em uma descompensação psíquica em que a pessoa acaba questionando sua percepção sobre a realidade e podendo perder a confiança em si e duvidando de sua própria identidade (MARROM apud FERREIRA, SOUZA e MOREIRA, 2015, p. 1575).

Ser assumido ou ser gay afeminado é outra dificuldade ao ingresso ou fato para terem menores chances diante das oportunidades de entrar no mundo do trabalho: "As dificuldades em conseguir um emprego ou firmar-se em uma profissão realmente existem para as pessoas que se declaram abertamente homossexuais, principalmente aquelas que possuem características femininas. Sendo esse aspecto levantado na maioria das entrevistas" (MARROM apud FERREIRA; SOUZA; MOREIRA, 2015, p. 1579). De modo que se propõe a seguinte indagação: 
Um Estado democrático de direito não pode aceitar práticas sociais e institucionais que criminalizam, estigmatizam e marginalizam as pessoas por motivo de sexo, orientação sexual e/ou identidade de gênero. Portanto, o Estado assume a responsabilidade de implementar políticas públicas que tenham como foco a população LGBT, visando a consolidação da orientação sexual e da identidade de gênero a fim de romper essa lógica injustiça (FERREIRA, SOUZA e MOREIRA, 2015, p. 1581).

O estudo do Estado democrático de direito e a responsabilidade do Estado é fundamental, principalmente no que se refere a políticas públicas que visem minimizar o sofrimento da comunidade LGBT e os desafios que precisam ser vencidos. Torna-se relevante para auxiliar os governantes, poder legislativo e sociedade civil a identificar e planejar quais mudanças legais necessitam ser implantadas ou implementadas com a finalidade de tornar as pessoas e o mundo mais humano e resiliente, contribuindo com a garantia de mais direitos e igualdade de oportunidades que as demais pessoas que não fazem parte do grupo tem, disseminando o respeito as diferenças humanas.

\section{Homofobia X Combate a Homofobia nas Organizações}

É o ódio ou o conjunto de atitudes que tem como finalidade atingir o homossexual, que seja fisicamente ou psicologicamente. Fazendo-o sentir humilhado, desprezado, coagido, constrangido. Essa manifestação tem por intuito excluí-los do meio em que a pessoa está e da sociedade. Fazendo com que eles se sintam diminuídos, se fechem e se revoltem com o mundo. Ferreira (2007, p.33) define a homofobia:

\footnotetext{
Usada para definir a repulsa de alguns indivíduos face ás relações afetivas e sexuais entre pessoas do mesmo sexo, ela é caracterizada pelo medo e desprezo pelos homossexuais, muitas vezes por se considerar crenças que assumem que a heterossexualidade é a única forma de sexualidade normal, natural e aceitável. O homossexualismo para quem pratica a homofobia é uma doença.
}

A Constituição Federal no seu Art. $3^{\circ}$, IV, tem o objetivo de não permitir o desenvolvimento da homofobia da seguinte forma: "promover o bem de todos, sem preconceitos de origem, raça, sexo, cor, idade e quaisquer outras formas de discriminação". A homofobia seria visualidade quando se diz outras formas. A homofobia também fere a declaração dos direitos humanos, pelo fato do não tolerar, do discriminar, de alguma forma ofender ou repudiar um indivíduo igual e com os mesmos direitos que o outro, mas que na prática quem age com 
homofobia mostra o contrário. Quem pratica a homofobia comete um crime que fere a honra do indivíduo, ou vai contra esse princípio. Se um LGBT for vítima de injúria ou ocorrer um ato mais grave de homofobia, que seria o homicídio, nesse caso a pena aumenta (Art. 140 e Art. 121, §2º II, ambos do Código Penal):

\author{
Art. 121. Matar alguém: \\ Pena - reclusão, de seis a vinte anos. \\ $\S 2 \circ$ Se o homicídio é cometido: \\ II - por motivo fútil; \\ Art. 140 - Injuriar alguém, ofendendo-lhe a dignidade ou o decoro: \\ Pena - detenção, de um a seis meses, ou multa. \\ $\S 2^{\circ}$ - Se a injúria consiste em violência ou vias de fato, que, por sua natureza ou pelo \\ meio empregado, se considerem aviltantes: \\ Pena - detenção, de três meses a um ano, e multa, além da pena correspondente à \\ violência (DECRETO-LEI No 2.848, de 07 DE DEZEMBRO DE 1940).
}

É necessário que a conscientização dos direitos do ser humano seja sempre reforçada, para que com uma atitude de respeito todos possam compreender que somos iguais perante a lei.

\footnotetext{
Os discursos que nos oprimem, lésbicas, mulheres e homens gays, em particular, são aqueles que partem da premissa de que toda e qualquer sociedade é fundada apenas por vivências heterossexuais, direcionadas por homens heterossexuais[...]. Estes discursos nos oprimem, no sentido de que eles impedem que falemos por nós. Estes discursos recusam-se a dar-nos voz e oportunidades para criarmos as nossas próprias categorias (WITTIG, 1980

[1992], p. 22 apud MELO, 2017).
}

Algumas exposições de opiniões, ideias e pensamentos em determinadas situações exprime a falta de liberdade das pessoas de serem quem elas gostariam de ser, de viverem conforme buscam. $\mathrm{O}$ fato da sociedade em sua maioria ser formada por pessoas heterossexuais faz com que o diferente seja encarado como um problema e não como uma oportunidade de conviver com as diferenças, de lidar com o novo e superar os desafios de forma a querer sempre o bem do outro. A voz deve ser dada a qualquer pessoa que precisa falar e precisa defender os seus direitos e interesses. Um país democrático se faz dando a igualdade de direitos e deveres para todas as pessoas, como também fazendo com que estas tenham liberdade de expressão. 


\title{
Conquistando Direitos
}

Vale salientar o preâmbulo da Constituição da República Federativa do Brasil de 1988 apregoa que:

\begin{abstract}
Nós, representantes do povo brasileiro, reunidos em Assembleia Nacional Constituinte para instituir um Estado Democrático, destinado a assegurar o exercício dos direitos sociais e individuais, a liberdade, a segurança, o bem-estar, o desenvolvimento, a igualdade e a justiça como valores supremos de uma sociedade fraterna, pluralista e sem preconceitos, fundada na harmonia social e comprometida, na ordem interna e internacional, com a solução pacífica das controvérsias, promulgamos, sob a proteção de Deus, a seguinte (CONSTITUIÇÃO DA REPÚBLICA FEDERATIVA DO BRASIL DE 1988).
\end{abstract}

O Art. $1^{\circ}$, inciso III, da Constituição da República Federativa do Brasil fala dos princípios fundamentais e destaca ou assegura "a dignidade da pessoa humana". A república é formada pelo município, estado e distrito federal e todos devem dar importância e proporcionar aos indivíduos a garantia desse direito (direitos e garantias fundamentais ao indivíduo). Por conseguinte, destacam-se alguns artigos importantes:

\section{DOS PRINCÍPIOS FUNDAMENTAIS}

$1^{\circ}$ A República Federativa do Brasil, formada pela união indissolúvel dos Estados e Municípios e do Distrito Federal, constitui-se em Estado Democrático de Direito e tem como fundamentos: III - a dignidade da pessoa humana;

Art. $3^{\circ}$ Constituem objetivos fundamentais da República Federativa do Brasil: I construir uma sociedade livre, justa e solidária; II - garantir o desenvolvimento nacional; II - erradicar a pobreza e a marginalização e reduzir as desigualdades sociais e regionais; IV - promover o bem de todos, sem preconceitos de origem, raça, sexo, cor, idade e quaisquer outras formas de discriminação (CONSTITUIÇÃO DA REPÚBLICA FEDERATIVA DO BRASIL DE 1988).

Concomitantemente, é fundamental ressaltar que os princípios fundamentais asseveram que é de inteira responsabilidade do Estado a seguridade ao princípio da dignidade da pessoa humana, como também garantir o bem de todos, sem preconceitos de origem, raça, sexo, cor, idade e quaisquer outras formas de discriminação, tendo os demais princípios como aliados:

\section{DOS DIREITOS E DEVERES INDIVIDUAIS E COLETIVOS}

Art. $5^{\circ}$ Todos são iguais perante a lei, sem distinção de qualquer natureza, garantindose aos brasileiros e aos estrangeiros residentes no País a inviolabilidade do direito à vida, à liberdade, à igualdade, à segurança e à propriedade, nos termos seguintes: I homens e mulheres são iguais em direitos e obrigações, nos termos desta Constituição; III - ninguém será submetido a tortura nem a tratamento desumano ou degradante; X - são invioláveis a intimidade, a vida privada, a honra e a imagem das pessoas, assegurado o direito à indenização pelo dano material ou moral decorrente de sua violação; XLI - a lei punirá qualquer discriminação atentatória dos direitos e liberdades fundamentais; 
$\S 1^{\circ}$ As normas definidoras dos direitos e garantias fundamentais têm aplicação imediata (CONSTITUIÇÃO DA REPÚBLICA FEDERATIVA DO BRASIL DE 1988).

Se faz necessário mencionar os direitos e deveres individuais e coletivos das pessoas a fim de informá-los e conscientizá-los do que pode ou não ser feito. Em lei, ou seja, de forma escrita todas as pessoas têm o mesmo direito não podem e não devem ser retirados de nenhum indivíduo, sendo nesse sentido necessário a luta por eles para que de fato funcione fora do papel, pois de nada adianta uma lei criada se ela não é executada como se propõe. Necessita-se também que tanto os direitos e deveres sejam cumpridos para que o ser humano tenha uma vida digna e plena.

\section{DOS DIREITOS SOCIAIS}

Art. $6^{\circ}$ São direitos sociais a educação, a saúde, a alimentação, o trabalho, a moradia, o lazer, a segurança, a previdência social, a proteção à maternidade e à infância, a assistência aos desamparados, na forma desta Constituição.

Art. $7^{\circ}$ São direitos dos trabalhadores urbanos e rurais, além de outros que visem à melhoria de sua condição social: I - relação de emprego protegida contra despedida arbitrária ou sem justa causa, nos termos de lei complementar, que preverá indenização compensatória, dentre outros direitos (CONSTITUIÇÃO DA REPÚBLICA FEDERATIVA DO BRASIL DE 1988).

Os direitos sociais são enfatizados porque buscam a qualidade de vida dos indivíduos, sendo parte essencial daquilo que o Estado deve garantir a estes. Objetiva-se com isso melhorar as condições de vida de uma pessoa bem como as relações de vínculo de trabalho, garantindo cada vez mais a uma quantidade maior de pessoas sem fazer nenhum tipo de distinção entre elas, ou seja, oferecendo as mesmas oportunidades.

\section{DOS PRINCÍPIOS GERAIS DA ATIVIDADE ECONÔMICA}

Art. 170. A ordem econômica, fundada na valorização do trabalho humano e na livre iniciativa, tem por fim assegurar a todos existência digna, conforme os ditames da justiça social, observados os seguintes princípios:

I - soberania nacional;

II - propriedade privada;

III - função social da propriedade;

IV - livre concorrência;

$\mathrm{V}$ - defesa do consumidor;

(CONSTITUIÇÃO DA REPÚBLICA FEDERATIVA DO BRASIL DE 1988).

O artigo 170 é enfatizado porque menciona a ordem econômica, trabalhando normas constitucionais que buscam a definição de um modelo para a economia e de que forma o estado pode intervir nesse contexto a fim de assegurar a todos uma existência digna.

Art. 193. A ordem social tem como base o primado do trabalho, e como objetivo o bem-estar e a justiça social. 
Art. 225. Todos têm direito ao meio ambiente ecologicamente equilibrado, bem de uso comum do povo e essencial à sadia qualidade de vida, impondo-se ao Poder Público e à coletividade o dever de defendê-lo e preservá-lo para as presentes e futuras gerações (CONSTITUIÇÃO DA REPÚBLICA FEDERATIVA DO BRASIL DE 1988).

Por fim o artigo 193 é importante porque visa garantir o bem-estar social e a justiça social, e o artigo 225 tem destaque porque busca garantir um ambiente equilibrado que promova à sadia qualidade de vida, sendo dever do estado defendê-lo e preservá-lo não somente para as presentes gerações, mas para as futuras. Por sua vez, a Declaração Universal dos Direitos Humanos (DUDH) de 10 de dezembro de 1948, foi um importante marco para a história ao tornar público os direitos básicos de todo ser humano:

Artigo $1^{\circ}$ - Todos os seres humanos nascem livres e iguais em dignidade e direitos; Artigo $23^{\circ}$, I - Toda a pessoa tem direito ao trabalho, à livre escolha do trabalho, a condições equitativas e satisfatórias de trabalho e à proteção contra o desemprego; II. Todos têm direito, sem discriminação alguma, a salário igual por trabalho igual.

Santos (2006) sintetiza que os direitos que todos têm frente à declaração dos direitos humanos fundamentam-se no direito à vida, a liberdade, a segurança pessoal, a constituir família, a propriedade, a liberdade de pensamento, ao trabalho, ao lazer, a saúde, a educação. Por conseguinte, o autor questiona como pode um ser humano ter direitos reduzidos por apenas se relacionar afetivo ou sexualmente com outra pessoa, por ser privado (a) de determinado direito apenas por sua orientação sexual e/ ou por sua identidade de gênero? De fato, é inadmissível em pleno século XXI perceber que empresas e pessoas fecham portas para um ser humano por ele ser um membro LGBT, desrespeitam o direito de ser diferente.

Cabe a todos que pensam desta forma criar maneiras de fazer valer a lei, bem como implementar as existentes para que o respeito seja disseminado, contribuindo com a melhoria de vida desse grupo de pessoas, assim como alcançar uma maior inserção no mundo do trabalho, para que os mesmos tenham uma voz mais ativa.

A Lei $\mathrm{n}^{\mathrm{o}} .10 .406$ de 10 de janeiro de 2002, que instituiu o novo Código Civil, assevera em seus artigos 186 e 187 quais são as situações que podem resultar em uma indenização por danos morais:

Art. 186. Aquele que, por ação ou omissão voluntária, negligência ou imprudência, violar direito e causar dano a outrem, ainda que exclusivamente moral, comete ato ilícito.

Art. 187. Também comete ato ilícito o titular de um direito que, ao exercê-lo, excede manifestamente os limites impostos pelo seu fim econômico ou social, pela boa-fé ou pelos bons costumes.

(LEI N 10.406, DE 10 DE JANEIRO DE 2002). 
Desse modo os artigos citados acima destacam aquilo que é ilegal, proibido, assim como moralmente errado, fazendo-se com que as pessoas que cometem tal crime reparem o ato com uma indenização por danos morais. Vale ressaltar que dinheiro algum apaga da memória o sofrimento vivido pela vítima, porém é uma forma de fazer com que os indivíduos reflitam as suas ações que são reprováveis para um convívio social. Já no Decreto-Lei no 2.848 de 07 de dezembro de 1940, lei regulamentadora do Código Penal brasileiro, aponta em seus artigos 146 e 147 as situações de constrangimento ilegal que podem resultar em detenção ou pagamento de multa aos indivíduos que cometem tal crime.

\author{
Constrangimento ilegal \\ Art. 146 - Constranger alguém, mediante violência ou grave ameaça, ou depois de lhe \\ haver reduzido, por qualquer outro meio, a capacidade de resistência, a não fazer o \\ que a lei permite, ou fazer o que ela não manda: Pena - detenção, de 3(três) meses a \\ 1(um) ano, ou multa. \\ Art. 147 - Ameaçar alguém, por palavra, escrito ou gesto, ou qualquer outro meio \\ simbólico, de causar-lhe mal injusto e grave: \\ Pena - detenção, de um a seis meses, ou multa.
}

(DECRETO-LEI No 2.848, DE 7 DE DEZEMBRO DE 1940).

Desse modo os artigos citados acima destacam aquilo que também é ilegal, proibido, fazendo-se com que as pessoas que cometem tal crime reparem o ato através da detenção ou pagamento de multa. Talvez a vítima enxergue a detenção como uma forma mais fácil de minimizar o sofrimento vivenciado, pois trata-se de uma exclusão social, de oferecer um espaço limitado para que o mesmo sinta na pele a redução da sua liberdade, passando na cabeça da vítima que o mesmo terá tempo para refletir as suas ações e atitudes. Finalmente, o Decreto-Lei $\mathrm{n}^{\circ} 5.452$ de $1^{\circ}$ de maio de 1943 que passou a regulamentar a Consolidação das Leis do Trabalho, apresenta alguns casos em que pode ser rescindido o contrato pela má conduta do trabalho por parte do empregador, podendo assim o empregado requerer uma indenização:

\title{
DA RESCISÃO
}

Art. 483 - O empregado poderá considerar rescindido o contrato e pleitear a devida indenização quando:

a) forem exigidos serviços superiores às suas forças, defesos por lei, contrários aos bons costumes, ou alheios ao contrato;

b) for tratado pelo empregador ou por seus superiores hierárquicos com rigor excessivo;

c) correr perigo manifesto de mal considerável;

d) não cumprir o empregador as obrigações do contrato;

e) praticar o empregador ou seus prepostos, contra ele ou pessoas de sua família, ato lesivo da honra e boa fama;

f) o empregador ou seus prepostos ofenderem-no fisicamente, salvo em caso de legítima defesa, própria ou de outrem; 
g) o empregador reduzir o seu trabalho, sendo este por peça ou tarefa, de forma a afetar sensivelmente a importância dos salários.

$\S 1^{\circ}$ - O empregado poderá suspender a prestação dos serviços ou rescindir o contrato, quando tiver de desempenhar obrigações legais, incompatíveis com a continuação do serviço.

$\S 2^{\circ}$ - No caso de morte do empregador constituído em empresa individual, é facultado ao empregado rescindir o contrato de trabalho.

$\S 3^{\circ}$ - Nas hipóteses das letras "d" e "g", poderá o empregado pleitear a rescisão de seu contrato de trabalho e o pagamento das respectivas indenizações, permanecendo ou não no serviço até final decisão do processo.

(DECRETO-LEI No 5.452, de $1^{\circ}$ de Maio de 1943).

A Consolidação das Leis de Trabalho (CLT) se faz necessário para garantir ainda mais os direitos dos trabalhadores unificando toda a lei no Brasil, protegendo os trabalhadores do excesso de poder exercido na relação empregador e empregado, e regulando as questões individuais e coletivas.

\title{
Diversidade Sexual: A Inclusão e o Respeito às Diferenças
}

De acordo com a Secretaria de Estado dos Direitos Humanos e Cidadania do Maranhão (2009, p. 14):

\begin{abstract}
É preciso educar para a diversidade sexual: A educação em direitos humanos tem um importante papel no respeito à diversidade sexual e a identidade de gênero, pois ao mesmo tempo em que promove valores de respeito às diferentes formas de orientação sexual, atua também no agir e no sentir das pessoas de modo a combater a discriminação e a homofobia. Educar para a diversidade é educar, portanto, para o respeito às diferenças entre toda e qualquer pessoa.
\end{abstract}

A educação traz a oportunidade de mudança, de aceitar e respeitar as opiniões e expressões dos indivíduos seja no campo sexual ou não. A partir desse fundamento passamos a dar mais importância à oportunidade de incluir as pessoas, que julgamos diferente de nós em todos os contextos sociais, dentre elas no ambiente de trabalho. Através da aceitação que todos somos diferentes seja na aparência física, na forma de pensar entre outros, mais que somos e sempre seremos iguais no direito à dignidade e a oportunidades.

A partir do momento que os seres humanos aceitam que todos são iguais no direito à dignidade e a oportunidade, e que deve existir o respeito as diferenças existentes entre eles, seja na aparência física, na forma de pensar entre outros, será proporcionado o desenvolvimento do outro e consequentemente o de quem pensa e age desta forma. A inclusão social é uma excelente forma de conviver com pessoas diferentes e aprender a respeitá-las, desenvolvendo-as em todos 
os aspectos e encontrando nelas a competência profissional facilmente percebida em pessoas heterossexuais.

\section{Metodologia}

Para atender os objetivos descritos na pesquisa foram adotados os seguintes procedimentos metodológicos: Foi realizada inicialmente uma pesquisa bibliográfica com base em livros, artigos e sites científicos relacionados ao assédio moral de LGBT no âmbito organizacional. Posteriormente realizou-se um levantamento de dados primários com o interesse de entender este cenário não somente na teoria mais compreender o seu formato na vida prática de um dos representantes da comunidade LGBT, como investigar o posicionamento de uma gestora de uma empresa privada, isto é, de uma empresária frente ao assunto do trabalho e estudo.

A pesquisa está classificada como de natureza básica, pois "é aquela sem finalidades imediatas e que o conhecimento gerado por ela vai ser utilizado em pesquisas aplicadas ou tecnológicas" (PEREIRA, 2012, p.90).

Frente aos objetivos a pesquisa foi exploratória e descritiva (CERVO; BERVIAN, 2002). Teve-se o propósito de trabalhar com a abordagem qualitativa, pois a pesquisa qualitativa é, às vezes, superior no processo de identificação de problemas que em muitas situações passam despercebidas quando se tem um estudo com abordagem quantitativa, assim os sujeitos participantes da pesquisa qualitativa sentem-se mais à vontade para responder aos questionamentos como para dizer ao pesquisador o que lhes interessa (MC DANIEL; GATES, 2004). Utiliza-se de dois estudos de caso, um com um homossexual gay e o outro com uma empresária heterossexual (GIL, 2010).

O estudo foi realizado no município de Juazeiro do Norte-CE, nos dias 24 e 26 de outubro de 2017. Tal cidade apresenta uma população estimada em 270.383 , e está localizada na região metropolitana do Cariri, ao sul do estado do Ceará, segundo dados do Instituto Brasileiro de Geografia e Estatística (IBGE, 2017). Os sujeitos da pesquisa foram duas pessoas das quais uma era integrante ou representante do grupo LGBT, sendo com um homossexual gay, o qual falou das experiências adquiridas ao longo de sua vida profissional, e a outra era 
uma gestora de uma empresa privada, ou seja, com uma empresária. Ambos ficaram sabendo do intuito da pesquisa e decidiram responder aos questionamentos.

O local e sujeitos da pesquisa foram selecionados por conveniência e acessibilidade (MALHOTRA, 2005), porém os sujeitos só foram incluídos no estudo se pertencessem ou atuassem profissionalmente no município de Juazeiro do Norte-CE, e se caracterizassem como membro do grupo LGBT e gestor (a) de empresa privada ligados ao assunto assédio moral de LGBT no âmbito organizacional. No que se refere ao processo de exclusão os sujeitos passariam a ser excluídos do estudo se os pesquisadores não conseguissem realizar a coleta de dados com um dos sujeitos citados anteriormente e se não fizessem parte do município escolhido.

Para coletar os dados foi escolhido à entrevista como instrumento de coleta de dados, pois a mesma pode ser compreendida como uma "técnica de coleta de informações sobre um determinado assunto, diretamente solicitadas aos sujeitos pesquisados. Trata-se, portanto, de uma interação entre pesquisador e pesquisado. $\mathrm{O}$ pesquisador visa apreender o que os sujeitos pensam, sabem, representam, fazem e argumentam" (SEVERINO, 2016, p.133). Foram utilizadas entrevistas semiestruturadas (LAVILLE; DIONNE, 1999; MARCONI; LAKATOS, 2010).

A entrevista direcionada para o LGBT continha 10 perguntas e as direcionada para a empresária continha a mesma quantidade, norteando os pontos que se gostaria de ter um maior detalhamento da situação. As perguntas foram elaboradas com uma linguagem simples e direta, a fim de uma melhor compreensão do que estava sendo perguntado por parte de quem respondia. Toda a entrevista foi gravada com a finalidade de não perder dados os quais são de extrema importância, e para registrar a forma como os respondentes se posicionavam em cada pergunta. Em resumo buscava-se reproduzir fielmente as respostas. Quanto à coleta dos dados ou fontes de dados para toda a pesquisa do artigo científico se utilizou de dados primários e secundários (MATTAR, 2005). A análise dos dados da presente pesquisa foi feita adotando-se a técnica de análise de conteúdo, que segundo Silva e Fossá (2013) é uma modalidade de apresentação de resultados de pesquisas qualitativas. Foi feita a transcrição de toda a entrevista e posteriormente o confronto com os autores do referencial teórico. 


\title{
Análise e Discussão dos Dados
}

A partir dos dados obtidos com a aplicação da entrevista, houve a transcrição das opiniões dos entrevistados onde a seguir estão dispostos os resultados e as análises obtidas através da realização das entrevistas respectivamente com: $7.1 \mathrm{um}$ representante do grupo LGBT, e 7.2 uma gestora de uma empresa privada, ou seja, com uma empresária.

\section{Estudo de Caso com um Representante do Grupo LGBT}

1-Você já foi impedido de ingressar numa vaga de trabalho por causa da sua orientação sexual, ou demitido por esse motivo? Comente.

\begin{abstract}
Sim. Já fui impedido e demitido várias vezes. Em relação a impedimento vou falar uma situação: Deixei um curriculum na empresa e fui selecionado. Recebi a ligação marcando a entrevista coletiva, com dinâmicas de grupo. Ao chegar lá à pessoa que estava selecionando já me olhou dos pés à cabeça, com olhar de espanto e desprezo que me constrangeu e me coagiu, mesmo assim permaneci no local. Diante da solicitação de que todos se apresentassem para a equipe, percebi que tinha a competência para ser admitido pela empresa, mas a vaga não era minha. Na última etapa que foi a entrevista pessoal, cara a cara com o selecionador ele me disse que eu não tinha e nunca terei condições de ser contratado pela empresa, por conta da aparência, da voz afeminada e porque a empresa não contratava LGBT. Em relação à demissão aconteceu esse fato: Trabalhava na empresa a um bom tempo e houve uma mudança na gerência. Percebi que o novo gerente me tratava diferente dos demais, nunca ficava realizado com o meu trabalho e sempre colocava algum defeito, mandava fazer hora extra e os meus colegas raramente fazia, atribuía funções que não era minha. Resumindo: um dia ele me chamou em sua sala e disse que não queria mais os meus serviços, argumentando que pessoas como eu, com esse jeito, do meu tipo, não suportava ficar no mesmo ambiente. Então me demitiu (ENTREVISTADO HOMOSSEXUAL GAY, 2017).
\end{abstract}

Percebe-se que existe de fato o impedimento dos homossexuais de ingressarem no mercado de trabalho por causa da sua orientação sexual ou pela identidade de gênero, ou que acontece deles serem admitidos e em determinado momento acabarem saindo do trabalho pelo mesmo motivo. É visível a dificuldade de encontrarem oportunidades. Quando não se tem como trabalhar a pessoa não tem condições mínimas de viver com dignidade.

2-Você já foi vítima de Homofobia ou Assédio no ambiente de trabalho? Por quem sofreste? Relate um fato que mais o feriu. 
Sim. Com certeza. Já fui vítima dos dois. Já sofri pelos gestores, pelos colegas de trabalho, pelos clientes. Enfim por parte de todos os envolvidos na empresa. Tinha um gerente que costumava reclamar os funcionários na frente das pessoas, dos clientes. Chamava os funcionários de burro e lerdo e no meu caso acrescentava que não sabia por que ainda não tinha me demitido. Falava que ia quebrar a minha cara se fizesse as coisas erradas, pressionava-me fortemente. Em outra empresa acontecia isso: No momento que ia sempre beber água os colegas paravam de trabalhar e começavam a me observar, passava sempre calado, ouvia risos e conversinhas. Já cheguei a ouvir: olha ele, a frutinha, não sei por que ele está aqui, essa empresa é devagar demais, pega esse tipo de gente para trabalhar aqui, com a gente (ENTREVISTADO HOMOSSEXUAL GAY, 2017).

A população gay em algum momento da vida pode ser ou já foi vítima de Assédio ou Homofobia no ambiente de trabalho. Podem sofrer por diversas pessoas, sejam elas gestores, colegas de trabalho e até mesmo dos clientes. Estes ataques fere o indivíduo.

3-Dentro do grupo LGBT, você conhece alguém preconceituoso? Por quê? Por favor relate sua vivência.

Sim. Com certeza, conheço várias pessoas, posso falar até porque. O que acontece é que a sociedade é muito preconceituosa, essa posição que a sociedade tem, massacra psicologicamente o grupo LGBT, fazendo com que alguns, não se aceitem como são. E outra coisa que acontece, é que se influenciam pela maioria, que julga e condena e então passa a existir um questionamento "se são certos ou errados" (ENTREVISTADO HOMOSSEXUAL GAY, 2017).

A comunidade, população ou grupo LGBT composta por lésbicas, gays, bissexuais, travestis e transexuais sofrem bastante preconceito por sua orientação sexual ou identidade de gênero. A sociedade fortemente massacra-os por serem diferentes, por não seguirem a cultura de uma relação afetiva/sexual homem e mulher, por quebrarem as regras e fazerem escolhas completamente diferentes daquelas feitas pela maioria dos integrantes da sociedade, fazem com que o preconceito se manifeste e se espalhe como epidemia. Por esses fatos e pela sociedade ser tão representativa de pessoas que os discriminam, que os acham errados, então chega um momento em que um homossexual internaliza esse preconceito, vindo a dificultar ainda mais a sua vida. Por isso dentro do grupo LGBT existem homossexuais preconceituosos.

4- Qual a sua postura diante de uma exclusão e desrespeito aos LGBT no ambiente de trabalho?

Sou contra essa atitude. O respeito tem que estar acima de qualquer coisa, independente das suas escolhas sexuais. O que deveria diferenciar as pessoas nas organizações é a competência e o compromisso que temos no trabalho e não a opção sexual. Estamos em pleno século XXI e acho que essas atitudes de excluir já não 
cabem em uma sociedade moderna como a nossa (ENTREVISTADO HOMOSSEXUAL GAY, 2017).

A exclusão e o desrespeito ao LGBT não era para existir no ambiente de trabalho, pois todas as pessoas são livres para se expressarem e dignas de viverem em todo o meio social, seja no trabalho ou na vida em geral. É preciso ter uma postura de respeito para com as pessoas, independente da sua orientação sexual ou identidade de gênero. Todas as pessoas são capazes de mostrar competência e compromisso. E diante de uma exclusão e desrespeito é preciso se mostrar contra.

5-Qual o principal motivo que as empresas restringem ou dificulta a entrada do grupo LGBT?

Acredito que seja por questões culturais, tanto do empregador como dos clientes, pois viemos de uma cultura onde o homossexualismo é errado e eles deveriam viver a margem da sociedade. Esse pensamento hoje não foi extinto por completo como as empresas vivem dos clientes a opinião deles é decisiva na empregabilidade dos seus funcionários (ENTREVISTADO HOMOSSEXUAL GAY, 2017).

A principal causa ou motivo que levam as empresas a restringirem ou dificultar a entrada do grupo LGBT é a cultura que se vive, o padrão que a sociedade impõe como aceitável. O pensamento de não aceitar o homossexual pode partir do gestor, dos colegas de trabalho que em maioria podem não aceitar e dos clientes que é o foco de qualquer empresa. Sendo assim as empresas encontram motivos para não os contratar.

6- Qual o maior prejuízo para os LGBT diante das pequenas portas aberta no mercado de trabalho? E para a organização que prejuízo ela tem em não oportunizar vagas de trabalho, de que maneira ela é afetada?

Os LGBT são prejudicados em tudo. Fere a nossa dignidade. Somos massacrados psicologicamente, afeta a vida financeira e consequentemente a física e dificulta a interação social. Em resumo: Falta o mínimo de condições para se ter uma vida digna. Para as organizações o maior prejuízo seria a não oportunidade de desenvolver uma pessoa profissionalmente e de praticar a inclusão social. Não se mostrarem preocupados com a responsabilidade social (ENTREVISTADO HOMOSSEXUAL GAY, 2017).

Diante das pequenas portas abertas no mercado de trabalho, pode-se verificar a presença de vários prejuízos não somente para o LGBT que são os mais prejudicados, mas também para as organizações quando não oportunizam vagas de trabalho. De alguma forma, direta ou indiretamente sofrem prejuízos. De alguma maneira ela é afetada. 
7-Qual dos membros do grupo LGBT sofre mais assédio ou é mais vítima de Homofobia? Por quê?

Os travestis porque nitidamente percebe-se que são do sexo oposto daquele visualizado (ENTREVISTADO HOMOSSEXUAL GAY, 2017).

Todos os membros do grupo LGBT sofrem ou são vítimas de Assédio e Homofobia, principalmente se o físico o denuncia, sendo assim o Travesti é o membro do grupo que mais sofre.

8-Nos episódios de Assédio ou Homofobia sofrido por você chegou a procurar seus direitos? Por quê?

Sim, já procurei algumas vezes. O motivo pelo qual procuro é para que a justiça seja feita e me sinta com os meus direitos garantidos (ENTREVISTADO HOMOSSEXUAL GAY, 2017).

Embora não exista uma lei específica para o Assédio Moral ou Homofobia, em episódios sofridos por alguma pessoa, pode-se utilizar de outras leis para punir, penalizar e multar o indivíduo que comete tal ação. É de fundamental importância a busca pelos direitos que qualquer pessoa tem, através da justiça espera-se que os direitos sejam garantidos.

9- Que ferramenta você usaria para combater o Assédio Moral e a Homofobia no ambiente de trabalho?

O esforço para conseguir cargos mais elevados para através deste, ter uma maior persuasão das pessoas, influenciando elas acima de tudo ao respeito a todos os indivíduos, sem nenhuma distinção (ENTREVISTADO HOMOSSEXUAL GAY, 2017).

É preciso utilizar ferramentas que diminua e combata o Assédio Moral e a Homofobia no ambiente de trabalho. Cada pessoa poderia ajudar e pensar nestes assuntos, afinal o ser humano é capaz de mudar a si e o mundo.

10- Para você, porque existe o Assédio Moral no trabalho?

Para desestruturar a pessoa, o ambiente de trabalho, fazendo com que prevaleça a opinião e o objetivo do assediante (ENTREVISTADO HOMOSSEXUAL GAY, 2017). 
Existe o Assédio Moral no trabalho, por diversas razões e objetivos. Em síntese, os resultados mostrados anteriormente pelo entrevistado homossexual gay vêm confirmar as informações apresentadas pelos autores do referencial teórico.

\section{Estudo de Caso com uma Gestora de uma Empresa Privada, ou seja, com uma Empresária}

1-Você já impediu ou demitiu do trabalho alguém por causa da sua orientação sexual ou pela identidade de gênero adotada por este? Por quê?

Sim. Já impedi como já demiti, porque eu não concordo com a maneira de viver que eles escolheram, acho que essas pessoas já têm suas profissões determinadas (ENTREVISTADA EMPRESÁRIA HETEROSSEXUAL, 2017).

Alguns gestores ou organizações impedem e demitem do trabalho alguém por causa da orientação sexual ou pela identidade de gênero adotada por este. Por não aceitarem e não quererem conviver com pessoas que tenham opções afetivo-sexuais diferentes da sua, e internalizam que os LGBT já têm as profissões determinadas.

2-Você já praticou Homofobia ou Assédio no ambiente de trabalho? De que maneira?

Sim. Já pratiquei os dois. Aconteceu a seguinte situação: Contratei um funcionário, não aparentava ser gay e até o achei competente, bom funcionário, mas uma vez um rapaz veio buscá-lo no trabalho, fiquei observando e vi quando se beijaram na boca. De repente me subiu um nojo, uma ânsia de vômito e aquela repulsa, uma vontade de agredi-lo fisicamente, queria demiti-lo, porém não poderia e nem queria no momento arcar com as despesas trabalhistas, diante do contrato de trabalho rompido, isto é, teria que pagar os seus direitos legais. Então, passei a tratá-lo diferentemente, o rebaixava, criticava publicamente o que ele fazia, o torturava psicologicamente até certo ponto em que o mesmo não aguentando as situações, pediu a tão sonhada demissão (ENTREVISTADA EMPRESÁRIA HETEROSSEXUAL, 2017).

É comum a prática da Homofobia ou Assédio no ambiente de trabalho frente ao grupo LGBT. Diante de várias situações este problema, esta pratica é manifestada.

3- Qual a sua postura diante de uma exclusão e desrespeito aos LGBT na sua empresa?

Finjo que não vejo, prefiro não opinar, fico sempre calada e lá no fundo me sinto realizada, pôr as pessoas falarem o que eu tenho vontade de falar, mas naquele momento não posso expressar minha opinião (ENTREVISTADA EMPRESÁRIA HETEROSSEXUAL, 2017). 
Muitas vezes a postura adotada pela empresa é omissa diante de uma exclusão e desrespeito aos LGBT no âmbito do trabalho.

4-Qual o principal motivo que vocês empresários restringem ou dificultam a entrada do grupo LGBT no mercado de trabalho ou nas suas empresas?

Primeiramente por causa dos clientes, alguns podem apoiar os LGBT, mas a sua maioria não aceita e as empresas dependem dos clientes, vê-los satisfeitos é o nosso objetivo e a meta é o lucro. E em segundo, porque o perfil dos nossos funcionários tem que estar de acordo com os nossos princípios, ou seja, os princípios dos gestores (ENTREVISTADA EMPRESÁRIA HETEROSSEXUAL, 2017).

A maioria das empresas tem os clientes como principal motivo para restringirem ou dificultar a entrada do grupo LGBT no mercado de trabalho, alegando-se que não podem ir contra o desejo e cultura dos clientes.

5- Ao não contratar um LGBT, a sua organização tem algum prejuízo?

Acredito que não, porque se eu não concordo e não sou a favor das suas opções sexuais, porque razão eu os contrataria ou seria prejudicada pela ausência deles na empresa? Pelo contrário, sua contratação diminuiria minhas vendas e afastaria a maioria dos clientes que pensam iguais a mim. Vale ressaltar que são muitos, que pensam iguais a mim (ENTREVISTADA EMPRESÁRIA HETEROSSEXUAL, 2017).

Frente à empregabilidade dos LGBT, a empresária ao ser questionada sobre o possível prejuízo que sua organização teria em não contratar pessoas desse grupo, acaba por dizer que não tem nenhum prejuízo. E sim, que podem apresentar prejuízos se houver o processo de contratação.

6-Qual dos membros do grupo LGBT, você acha que sofre mais assédio ou é mais vítima de Homofobia nas empresas? Por quê?

Os travestis. Pela aparência física deles, por mais que eles tentem se vestir como mulheres e parecer o máximo com elas, ainda existem os traços masculinos, deixando nítido a sua verdadeira origem e isso causa constrangimento a todas as pessoas que vem até a empresa (ENTREVISTADA EMPRESÁRIA HETEROSSEXUAL, 2017).

Ao questionar qual dos membros do grupo LGBT pode, ou poderia sofrer mais assédio ou ser mais vítima de Homofobia nas empresas, seria facilmente identificado, sendo os travestis. 
7- Você divulga sua opinião em relação a esses assuntos no ambiente de trabalho? Por quê?

Sim. Com certeza, obviamente para pessoas mais confiáveis e íntimas, até porque hoje em dia tudo dá processo (ENTREVISTADA EMPRESÁRIA HETEROSSEXUAL, 2017).

A questão de divulgação da opinião das empresas, em relação a esses assuntos no ambiente de trabalho nem sempre acontece claramente e é percebida por todos, pois em determinadas organizações é mantido o alerta para a mesma não sofrer processos judiciais. Os gestores sabem manipular a situação e às vezes só assedia ou praticam a Homofobia com quem eles acham que não entraria na justiça.

8- Você acha que já influenciou outros empresários a barrar esse grupo no mercado de trabalho?

Já. Já influenciei. Eu falo mesmo. A mesma opinião que eu tenho, que estou falando, divulgo para outras pessoas e procuro convencer as mesmas a terem a mesma opinião (ENTREVISTADA EMPRESÁRIA HETEROSSEXUAL, 2017).

Além de algumas empresas serem contra os LGBT e barrarem esse grupo, ou seja, a sua entrada no mercado de trabalho ainda tentam disseminar o mesmo ponto de vista. Procuram persuadir, influenciar outros empresários a continuar dificultando a entrada dos mesmos.

9- Você como empresário acha que o assédio é algo recente ou que sempre existiu nas relações de trabalho?

Sempre existiu, pois desde que surgiram as relações de trabalho, relacionamento patrão e empregado, há o predomínio do poder. O poder que o patrão exerce sobre os liderados é visível e a todo o momento demonstrado. O empregador se vê como alguém que tem uma autoridade maior e muitas vezes usa essa condição para realizar ou satisfazer as suas vontades. O assédio aos LGBT acontece porque não aceitamos as diferenças existentes (ENTREVISTADA EMPRESÁRIA HETEROSSEXUAL, 2017).

O Assédio Moral não é recente, é um problema de muito tempo, que sempre existiu nas relações de trabalho, porém atualmente é mais estudado, os empresários sempre utilizaram.

10- A sua empresa já respondeu processos jurídicos frente a esses dois temas: Assédio Moral e Homofobia, ou conhece alguma que tenha respondido? 
Não, e não conheço ninguém que tenha respondido processos diante dos temas expostos. Acho que não deveria haver nenhuma represália, nenhuma punição. Ninguém deve responder processos jurídicos por expressar a sua opinião. Não vivemos em um país livre e democrático? (ENTREVISTADA EMPRESÁRIA HETEROSSEXUAL, 2017).

Em síntese, os resultados mostrados anteriormente pela entrevistada empresária vêm confirmar as informações apresentadas pelos autores do referencial teórico.

\section{Considerações Finais}

Este trabalho contribuiu para identificar a definição de assédio moral no trabalho, suas características, seus objetivos, suas causas, as consequências geradas tanto para o assediado como para o assediador e a classificação do assédio moral. Foi possível diferenciar corretamente a sigla LGBT, como também entender de forma mais detalhada o assédio moral focado nesse grupo minoritário em termos de direito.

Obteve-se um detalhamento da visão de mercado e das dificuldades enfrentadas pelo grupo, dificuldades estas relacionadas não somente ao ingresso no mercado de trabalho como também da permanência dos mesmos neste ambiente, onde simplesmente eles objetivam uma oportunidade de mostrar o seu trabalho, independente de sua orientação sexual ou identidade de gênero. Foi aprendido a definir homofobia e a percebê-la nas situações expostas pelos entrevistados, e foi dado um norte de como poderia haver a diminuição ou o combate nas organizações. Foi conhecido um pouco mais as leis que garantem ou que deveriam garantir o direito a dignidade da pessoa humana, bem como a inexistência de uma lei específica para o assédio moral frente à esfera privada, sendo de certa forma uma abertura para a sua prática.

Foi possível adentrar em alguns ramos do direto para mostrar que tem leis que podem ser aplicadas a prática do assédio. Recordou-se a declaração dos direitos humanos que foi um marco para todas as pessoas e países, pois é universal. O conhecimento da nossa constituição federativa brasileira onde a mesma busca uma garantia de um dos maiores direitos humanos, a dignidade da pessoa humana, fortalecendo o que A DUDH já havia dito. Foi aprendido o que seja diversidade sexual, a importância do respeito e da inclusão social, o seu impacto na empresa e na sociedade. 
Destaca-se também a importância dos casos práticos estudados, pois permitiu ser entendido de perto o posicionamento de ambos os entrevistados, para que fosse estudado os seus pontos fortes e fracos e assim procurar mobilizar as pessoas para o processo de mudança positiva para ambos os lados, tanto com relação a empresa quanto ao colaborador.

O presente estudo atingiu seus objetivos, no momento em que se identificou a existência de assédio moral de LGBT na organização pesquisada verificando-se as causas diante da percepção de uma empresária, e se constatou este assédio através das experiências de um representante do grupo, comprovando-se o que foi destacado na pesquisa bibliográfica.

Diante de todo o cenário apresentado é necessário que as empresas possam se preocupar com a responsabilidade social, com o impacto que a mesma causa à vida das pessoas, que se coloquem no lugar dos LGBT que se fossem eles, passando pela dificuldade de ingressarem no mercado de trabalho ou permanência dos mesmos nas organizações, que tivessem seus direitos negados, o maior direito de uma pessoa, a dignidade humana ferida, destruída por gestores, por colegas de trabalho, por clientes que pensam somente na sua cultura, nas suas crenças e opiniões, nesse caso não precisa pensar como eles, necessitam apenas do respeito e nos direitos ou oportunidades iguais as demais pessoas, pois o mesmo é competente, e o que define a competência jamais será a orientação sexual ou a identidade de gênero adotada por ser humano.

Todos nós inseridos na sociedade somos responsáveis diretamente ou indiretamente pelos problemas e resultados encontrados. As pessoas deveriam deixar de ser menos egoístas, bem como deixar de julgar o outro pelo que não se agradam, e sim olhar o outro e vê nele a oportunidade de desenvolvimento. Todos os envolvidos no contexto de trabalho, a sociedade no seu todo e o governo seja ele brasileiro ou não, precisam juntos mudar essa realidade.

É necessário promover a educação, o respeito ao outro, necessidade de participar, se informar, reivindicar, reclamar, influenciar o outro na busca de juntos se fortalecerem, na busca de mudança de pensamento, para depois mudança nas ações, é gritante essa necessidade. Não adianta querer melhorias se não encontrarem inicialmente dentro de si, e se costumam esperar sentados, sem nada fazer. A conquista só virá depois de muita luta. É preciso lutar para ver o progresso acontecer.

A pesquisa possui limitação em função de levar em consideração apenas duas pessoas, sendo uma integrante ou representante do grupo LGBT, e a outra uma gestora de uma empresa privada, ou seja, com uma empresária. Em função disso sugere-se novos estudos para que abranjam a quantidade de sujeitos investigados, a fim de uma maior representatividade. Poderia 
ser feito um confronto de uma empresa preocupada com a inclusão social com a empresa que não adota a inclusão.

Pesquisar de repente em outras cidades para confrontar os dados em questão, buscandose identificar se há uma postura diferente adotada frente ao assédio moral de LGBT no âmbito do trabalho.

Deixa-se a dica de investigar os colaboradores de uma empresa para saber a visão deles sobre esse assunto, até porque essa é também uma das classificações do assédio, os funcionários também praticam assédio como foi visto no desenrolar do artigo. Seria interessante utilizar dessa vez o questionário como uma forma de induzir os mesmos a ficarem mais livres para a análise das perguntas, pois não é fácil alguém falar que fez ou praticou algo que no julgamento de algumas pessoas ou visão seria errado, frente ao assédio moral, o problema talvez se apresente maior, pois é tudo contingencial.

\section{Referências}

BRASIL (A). Constituição da República Federativa do Brasil de 1988. Disponível em: <http://www.planalto.gov.br/ccivil_03/Constituicao/Constituicao.htm>. Acesso em: 22 ago.2017.

(B). Decreto-Lei N..$^{\circ}$ 5.452, de $1^{\circ}$ de Maio de 1943. Aprova a Consolidação das Leis do Trabalho. Disponível em: <http://www.planalto.gov.br/ccivil_03/DecretoLei/Del5452.htm>. Acesso em: 22 ago.2017.

(C). Decreto-Lei No 2.848, de 07 de Dezembro de 1940. Código Penal.

Disponível em: <http://www.planalto.gov.br/CCIVIL_03/Decreto-Lei/Del2848.htm>. Acesso em: 22 ago. 2017.

(D). Lei $\mathbf{N}^{0}$ 10.406, de 10 de Janeiro de 2002. Institui o Código Civil.

Disponível em: < http://www.planalto.gov.br/ccivil_03/Leis/2002/L10406.htm>. Acesso em: 22 ago.2017.

CARVALHO, Nordson Gonçalves de. Assédio moral na relação de trabalho. 1. ed. São Paulo: Rideel, 2009.

CERVO, Amado Luiz, BERVIAN, Pedro Alcino. Metodologia Científica. 5a Edição. São Paulo: Pearson Prentice Hall, 2002. 
Declaração Universal dos Direitos do Homem de 10 de Dezembro de 1948. Disponível em: <http://apcrsi.pt/legislacao/19481210_declaracao_universal_dos_direitos_humanos.pdf >. Acesso em: 22 ago. 2017.

FERREIRA, Breno de Oliveira. SOUZA, Ana Beatriz Laurindo. MOREIRA, Liliane Leite. "Mercado Colorido": Percepções de Gays sobre o mercado de trabalho de Teresina-PI. Revista Eletrônica Gestão \& Saúde ISSN: 1982-4785. Vol.06, №. 02, Ano 2015 p. 1564-84 Disponível em: <file:///C:/Users/alencar/Downloads/1338-7201-1-PB\%20(1).pdf>. Acesso em: 22 ago.2017.

, Renata Costa. O Gay no Ambiente de Trabalho: Análise dos Efeitos de Ser Gay nas Organizações Contemporâneas. 2007. 126 f. Dissertação (Mestrado em Administração de Empresas) - Universidade de Brasília, Brasília, 2007. Disponível em: <http://bdtd.bce.unb.br/tedesimplificado/tde_arquivos/61/TDE-2007-09-21T130539Z1793/Publico/Dissert_Renata\%20Costa.pdf>. Acesso em: 22 ago.2017.

GIL, Antônio Carlos. Como elaborar projetos de pesquisa. 5. ed. São Paulo: Atlas, 2010.

GOVERNO ESTADUAL DE SÃO PAULO. Diversidade sexual e a cidadania LGBT. São Paulo: SJDC/SP, 2014. 44p. Disponível em: <http://www.justica.sp.gov.br/StaticFiles/SJDC/ArquivosComuns/ProgramasProjetos/CPDS/ Cartilha_Diversidade_Sexual_ea_Cidadania_LGBT.pdf>. Acesso em: 22 ago.2017.

IBGE. IBGE Cidades. Disponível em: <https://cidades.ibge.gov.br/brasil/ce/juazeirodonorte/panorama>. Acessado em: 24 ago. 2017.

LAVILLE, Christian; DIONNE, Jean. A construção do Saber: manual de metodologia da pesquisa em ciências humanas. Porto Alegre: Artmed; Belo Horizonte: Editora UFMG, 1999.

MALHOTRA, Naresh K. Introdução à Pesquisa de Marketing. São Paulo: Prentice Hall, 2005 .

MARCONI, Marina de Andrade; LAKATOS, Eva Maria. Fundamentos da Metodologia Científica. 7 eds. São Paulo: Atlas, 2010.

MATTAR, Fauze Najib. Pesquisa de marketing: Metodologia, planejamento. 6 ed. São Paulo: Atlas, 2005.

MELO, Miguel Ângelo Silva de. As Representações Sociais da Violência e o Debate nas Ciências Sociais. In: SILVA, Lielton Maia, DUARTE, Sandra Mary, GOMES FILHO, Antoniel dos Santos. Violência de Gênero: resistência em tempos de crise no Brasil.- João Pessoa: Ideia, 2017. 34p: 65.

MENEGASSO, Maria Ester. Responsabilidade Social das empresas: um desafio para o serviço social. Katálysis n.5 jul./dez. 2001. Disponível em: <file:///C:/Users/alencar/Downloads/Dialnet-ResponsabilidadeSocialDasEmpresas2928210\%20(1).pdf>. Acesso em: 22 ago.2017. 
MC DANIEL, Carl; GATES, Roger. Pesquisa de marketing. Rio de janeiro: Thomson, 2004.

NASCIMENTO, Sônia Mascaro. Assédio Moral. 2. ed. São Paulo: Saraiva, 2011.

PEREIRA, José Matias. Manual de Metodologia da Pesquisa Científica. 3 ed. São Paulo: Atlas, 2012.

SANTOS, Alexandre. Direitos Fundamentais, cidadania, respeito à diferença e a diversidade. Outubro de 2006. 20 slides.

SECRETARIA DE ESTADO DOS DIREITOS HUMANOS E CIDADANIA DO MARANHÃO. Homofobia. $1^{\text {a }}$ Edição: 2009. Disponível em: <http://www.mpma.mp.br/arquivos/CAOPDH/cartilha_Homofobia.pdf $>$. Acesso em: 22 ago.2017.

SEVERINO, Antônio Joaquim. Metodologia do Trabalho Científico. 24 ed. São Paulo: Cortez, 2016.

SILVA, Andressa Hennig, FOSSÁ, Maria Ivete Trevisan. Análise de Conteúdo: Exemplo de Aplicação da Técnica para Análise de Dados Qualitativos. IV Encontro de Ensino e Pesquisa em Administração e Contabilidade. Brasília/DF - 3 a 5 de novembro de 2013. Disponível em: <http://www.anpad.org.br/admin/pdf/EnEPQ129.pdf>. Acesso em: 22 ago. 2017.

SOARES, Leandro Queiroz. Assédio Moral no Trabalho e Interações Socioprofissionais: "ou você interage do jeito deles ou vai ser humilhado até não aguentar mais". 2006. $180 \mathrm{f}$. Dissertação (Mestrado em Psicologia) - Universidade de Brasília, Brasília, 2006.

Disponível em: <http://repositorio.unb.br/bitstream/10482/3459/1/dissertacao\%20Leandro\%20Queiroz\%20So ares.pdf>. Acesso em: 22 ago.2017.

, Fernanda de Carvalho, DUARTE Bento Herculano. O Assédio Moral no Ordenamento Jurídico Brasileiro. R. Fórum Trabalhista - RFT | Belo Horizonte, ano 3, n. 11, p. 21-47, mar./abr. 2014. Disponível em: <http://www.editoraforum.com.br/ef/wpcontent/uploads/2014/06/O-assedio-moral-no-ordenamento-juridico-brasileiro.pdf $>$. Acesso em: 22 ago. 2017.

Como citar este artigo (Formato ABNT):

ALENCAR, Maria Patrícia de; SANTOS, Nágela Cristina G. dos; MELO, Miguel Ângelo S. de. Assédio Moral de LGBT no âmbito Organizacional. Id on Line Rev.Mult. Psic., 2018, vol.12, n.40, p.413-442. ISSN: 1981-1179.

Recebido: 06/04/2018

Aceito 13/04/2018 